\title{
Tetraspanin CDI $5 \mathrm{I}$ is a novel prognostic marker in poor outcome endometrial cancer
}

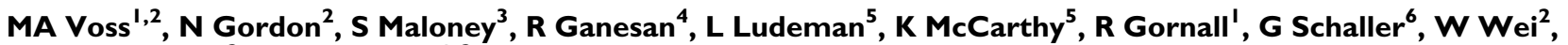 \\ F Berditchevski ${ }^{2}$ and $S$ Sundar ${ }^{*, 2}$
}

'Department of Obstetrics and Gynaecology, Cheltenham General Hospital, Gloucestershire, UK; ${ }^{2}$ Pan Birmingham gynaecological cancer centre, City Hospital, School of Cancer Sciences, University of Birmingham, Birmingham, UK; ${ }^{3}$ nstitute of Biomedical research, University of Birmingham, Birmingham, UK; ${ }^{4}$ Department of Pathology, Birmingham Womens Hospital NHS trust, Birmingham, UK; ${ }^{5}$ Department of Pathology, Cheltenham General Hospital, Gloucestershire, UK; ${ }^{6}$ Breast Care Institute (BCI), Munich, Germany

\begin{abstract}
BACKGROUND: Type II cancers account for 10\% of endometrial cancers but $50 \%$ of recurrence. Response rates to chemotherapy at recurrence are poor and better prognostic markers are needed to guide therapy. CDI5I is a small transmembrane protein that regulates cell migration and facilitates cancer metastasis. High CDI5I expression confers poor prognosis in breast, pancreatic and colorectal cancer. The prognostic significance of tetraspanin CDI5I expression in poor outcome endometrial cancers was evaluated, along with oestrogen receptor (ER), progesterone receptor (PR), p53, human epidermal growth factor receptor -2 (HER-2), and CD I5 I staining compared with $\alpha 6 \beta \mid, \alpha 3 \beta$ | integrins, and E-cadherin.

METHODS: Tissue microarray constructed from 156 poor outcome endometrial cancers, tested with immunohistochemistry and staining correlated with clinicopathological data were used. A total of 131 data sets were complete for analysis.

RESULTS: Expression of CD I I I was significantly higher in uterine papillary serous and clear cell carcinoma than in grade 3 endometrioid carcinoma, sarcoma or carcinosarcoma $(P<0.00 \mathrm{I})$. In univariate analysis, age, stage, histology type and CDI5I were significant for both recurrence free (RFS) and disease specific survival (DSS). In multivariate analyses, CDI5I was significant for RFS and DSS $(P=0.036$ and 0.033 , respectively) in triple negative (ER, PR and HER-2 negative) tumours (88/I3I). The HER-2, p53, ER and PR were not prognostic for survival. There was strong concordance of CDI5I with E-cadherin (98\%), but not with $\alpha 6 \beta$ | (35\%), $\alpha 3 \beta$ | staining (60\%).

CONCLUSION: The CDI 5 I is a novel marker in type 2 cancers that can guide therapeutic decisions. CD I 5 I may have an important role in tumourigenesis in some histology types.

British Journal of Cancer (2011) 104, 1611-1618. doi:10.1038/bjc.2011.80 www.bjcancer.com

Published online 19 April 20 II

(c) 20II Cancer Research UK
\end{abstract}

Keywords: endometrial cancer; tetraspanin CDI5I; prognostic marker; type II

Endometrial carcinoma is the most common neoplasm of the female genital tract in the United States and Europe with a worldwide estimated incidence in 2008 of 287000 cases and 74000 deaths from the disease (Ferlay et al, 2010). Endometrial cancer has increased by over $40 \%$ in the United Kingdom since 1993, to an incidence of 7536 in 2007 and 1741 deaths in 2008. (Cancer Research UK, 2010) This increase is attributed to increased life expectancy, tamoxifen use and obesity (Bray et al, 2005).

Endometrial cancer can be divided into oestrogen-dependent adenocarcinoma with endometrioid morphology (type I) and nonoestrogen-dependent adenocarcinoma (type II) predominantly with serous papillary or clear cell but also grade III endometrioid morphology (Bokhman, 1983; Rose, 1996). Molecular alterations involved in the development of endometrioid endometrial carcinomas are different from those of non-endometrioid carcinomas (Lax and Kurman, 1997). Type I carcinomas show more microsatellite instability, and mutations in the PTEN, K-RAS,

*Correspondence: Dr S Sundar; E-mail: s.s.sundar@bham.ac.uk Received 27 October 2010; revised 2 February 2011; accepted 7 February 201 I; published online 19 April $201 \mathrm{I}$
PIK3CA and $\beta$-catenin genes. Alterations of $\mathrm{p} 53$, STK15, p16, E-cadherin and HER-2 are more frequently found in type II cancers (Kohler et al, 1996; Risinger et al, 1998; Maxwell et al, 2001; Morrison et al, 2006).

Type I cancers are diagnosed at an early stage and have a good prognosis with $>95 \%$ 5-year survival. Although type II carcinomas only account for $10-20 \%$ of all endometrial malignancies (Bansal et al, 2009), they are responsible for $\sim 50 \%$ of all relapses (Carcangiu and Chambers, 1992, 1995; Levenback et al, 1992) and a low 5-year, all stage, overall survival rate of 35\% (Singh et al, 2008). Chemotherapy regimes in advanced stage and recurrent endometrial cancer have been disappointing, with a meta-analysis demonstrating a translated improvement in progression free survival by 1 month (pooled OR) with a concomitant significant impact on quality of life from intensive chemotherapy regimes (Humber et al, 2005). Few markers exist that can provide useful clinical guidance for decision making, particularly, as is usually the case, where the tumour marks negative for oestrogen (ER) and progesterone $(\mathrm{PR})$ receptors.

CD151 is one of 33 proteins in the mammalian tetraspanin superfamily, which has emerged as a key player in malignancy, the 
immune system, during fertilisation and infectious disease processes (Hemler, 2008). The CD151 is a widely expressed transmembrane protein, which is abundantly present on the surface of various types of normal epithelial cells that make contact with the basement membrane. Tetraspanins have a key role in the formation of tetraspanin-enriched microdomains (TERM or TEM), which also contain a number of other transmembrane receptors (e.g., integrins, receptors tyrosine kinases). Laminin-binding integrins (i.e., $\alpha 3 \beta 1, \alpha 6 \beta 1, \alpha 6 \beta 4, \alpha 7 \beta 1$ ) are most commonly associated with TEMs and it has been shown that tetraspanins regulate integrin-dependent adhesion strengthening, cell spreading and migration (Yanez-Mo et al, 1998; Sincock et al, 1999; Lammerding et al, 2003). Integrin-tetraspanin complexes are critical for regulating cell invasiveness and controlling intercellular interactions, both of which have a critical role during the metastatic progression (Stipp, 2010). In breast cancer, CD151 expression is increased in patients with invasive ductal carcinomas and this correlates with higher tumour grade and node metastasis. Importantly, CD151 was found to be a significant marker for poor outcome (Novitskaya et al, 2010; Sadej et al, 2010). The CD151 has also been validated as a significant prognostic marker of outcome in lung and prostate cancers (Tokuhara et al, 2001; Ang et al, 2004).

In this study, we investigate a cohort of endometrial cancers, characterised clinically by poor histological features and anticipated poor survival. The prognostic significance of CD151 expression was assessed and compared with clinicopathological features and previously used markers ER, PR, p53 and HER-2 in patients with poor outcome endometrial cancer. We also compared expression of CD151 with its binding integrin partners $-\alpha 6 \beta 1$, and $\alpha 3 \beta 1$, and with E-cadherin in the tissue microarray.

\section{PATIENTS AND METHODS}

\section{Patients and specimen characteristics}

Upon approval from the Southmead research ethics committee (REC ref. 07/H0102/64), archived paraffin-embedded tissue blocks were collected from all women who underwent treatment for International Federation of Gynaecology and Obstetrics (FIGO) stage IA-IV uterine cancers at the Gloucestershire NHS Foundation Trust Hospitals between 1997 and 2002. Histology types grade 3 endometrial adenocarcinoma (G3 EEC), uterine papillary serous cancer (UPSC), clear cell carcinoma (CC), carcinosarcoma (MMMT) and sarcoma were selected. Clinicopathological information and survival data were abstracted from a regional prospectively collected clinical database held at the South West Public Health Observatory (SWPHO; Bristol, UK). A total of $85.9 \%$ of patients underwent total abdominal hysterectomy with bilateral salpingo-oophorectomy and peritoneal washings, in some women pelvic node sampling was performed if they had been recruited to the ASTEC trial (Kitchener et al, 2009). This was consistent with surgical practice in the United Kingdom, in the study time period. Patients without gross peritoneal disease and lymphadenectomy were staged according to the extent of uterine involvement. Adjuvant platinum based chemotherapy or pelvic radiation was given at the discretion of the multidisciplinary team according to local guidelines. No patient received chemotherapy or radiotherapy before surgery. Patients were kept under surveillance for 5 years, longer follow-up details were abstracted from hospital records from other attendances. Clinical endpoints were survival or death of disease or other causes or date of recurrence as recorded in the hospital notes. Data were cross-referenced against cancer registry data to ensure accuracy.

\section{Tissue microarray construction}

Hematoxylin- and eosin-stained slides of tumours were reviewed to confirm original diagnosis and two separate representative areas of tumour marked on a corresponding paraffin block. Tissue biopsies of $0.6 \mathrm{~mm}$ diameter were taken from each donor block and mounted in a recipient block using a tissue array machine. (Beecher Instruments, Sun Prairie, WI, USA) Cores were set at $1 \mathrm{~mm}$ intervals, two cores per case, to decrease the risk of aberrant results due to tumour heterogeneity. Completed array blocks were sealed for $10 \mathrm{~min}$ in a $60^{\circ} \mathrm{C}$ oven. The tissue array was monitored by hematoxylin- and eosin-stain and in case of lack of visible tumour a duplicate biopsy processed.

\section{Immunohistochemistry}

The $4 \mu \mathrm{m}$ paraffin sections from the array blocks were used. Mouse anti-CD151 monoclonal antibody (mAb) The NCL-CD151 (Novocastra, Newcastle, Upon Tyne, UK) was used at dilution 1:50 (Berditchevski et al, 1997). Positive and negative controls were samples of breast cancer and normal breast, respectively. After $16 \mathrm{~h}$ antigen retrieval with $1 \times 1 \mathrm{~mm}$ EDTA pH 8.0, 0.1\% Tween 20 buffer, immunostaining was carried out using standard avidinbiotin-peroxidase complex method in the Shandon Sequenza Immunostaining Station. (Thermo Electron Corp. US, Waltham, MA, USA).

Cell surface adhesion molecules goat anti-human $\alpha 3$ integrin subunit (Santa Cruz, Santa Cruz, CA, USA, sc-6588, antibody concentration $0.67 \mu \mathrm{g} \mathrm{ml}^{-1}$; dilution $1: 300$ ), rabbit anti-human $\alpha 6$ integrin subunit (Santa Cruz, sc-10730, antibody concentration $0.5 \mu \mathrm{g} \mathrm{ml}^{-1}$; dilution $1: 400$ ) and mouse anti-E-cadherin (clone NCH-38, Dako (Copenhagen, Denmark), antibody concentration $0.1 \mu \mathrm{g} \mathrm{ml}^{-1}$; dilution $\left.1: 2000\right)$ were used. The W-CAP TEC buffer pH 8.0 (Bio-Optica Milano s.p.a, Milan, Italy) was used in threestep preparation. Sections were quenched in $0.3 \% \mathrm{H}_{2} \mathrm{O}_{2}$ in distilled water before primary antibody incubation at $4{ }^{\circ} \mathrm{C}$ for $16 \mathrm{~h}$. The R.T.U Vectastain Universal Quick kit (Vector laboratory, Burlingame, CA, USA), and Dako Real Envision DAB chromagen and solution (product: K5007, Dako) were used to detect both $\alpha 3 \beta 1$ and $\alpha 6 \beta 1$. Sections of ductal carcinoma in situ (with skin) were used as a positive tissue control.

Antibodies to oestrogen receptor (ER) (1D5 clone, Dako, Code M7047, total protein concentration $11.9 \mathrm{gl}^{-1}$, dilution of $1: 35$ ), progesterone receptor (PR) (PgR 636 clone, Dako, Code M3569, dilution of $1: 35$ ) and p53 (D-07 clone, Dako, Code M7001, total protein concentration $11.9 \mathrm{gl}^{-1}$, dilution $1: 50$ ) were used. Heat induced epitope retrieval was carried out using Antigen Access Unit (A. Menarini Diagnostics, Workingham, UK). Dako Auto Stainer universal platforms were used for staining.

The expression of HER-2 was evaluated in an accredited laboratory using Pathway HER-2 (Clone CB11) on the BenchMark XT automated system (Ventana Medical Systems Inc., Tucson, AZ, USA) and HER-2 antibody: A0485 clone (polyclonal antibody, Dako, HercepTest, dilution of $1: 400$ ) was used with known positive and negative breast cancer cell cultures included as controls.

Positive staining for CD151 was defined by crisp cytoplasmic and partly membranous staining, ER and PR by clear nuclear staining, p53 by unequivocal strong nuclear staining, HER-2 by clear membranous staining; $\alpha 3 \beta 1, \alpha 6 \beta 1$ integrins by cytoplasmic and membranous staining and E-cadherin by strong membranous staining.

\section{Evaluation of immunohistochemical staining}

All markers were evaluated independently, using light microscopy at $\times 400$ magnification by two pathologists blinded to the data on at least two separate occasions. In event of intra-observer or interobserver variation a consensus score was decided after examination at a multi-headed microscope. CD151, ER, PR and p53 were scored in a semi-quantitative manner incorporating both intensity of staining and distribution. Staining intensity (I) was graded as 0 
(no staining), 1 (weak), 2 (moderate), or 3 (strong). The proportion $(\mathrm{P})$ of cells $(0-100 \%)$ with the observed staining intensity was recorded. A score (histologic or H-score) was determined as the product of the intensity and proportion using the formula $(\mathrm{H}=\mathrm{I} \times \mathrm{P})$ (Budwit-Novotny et al, 1986; Katz et al, 1990; Wilder et al, 2004). H-score $=(1 \times$ percentage of cells stained at intensity category 1$)+(2 \times$ percentage of cells stained at intensity category 2$)+(3 \times$ percentage of cells stained at intensity category 3 ). H-score between 0 and 300 was obtained where 300 was equal to $100 \%$ of tumour cells stained strongly. H-score $\geqslant 150$ was considered positive for the above markers. HER-2 scores were evaluated by a pathologist (GS) as per established guidelines (Wolff et al, 2007). Cases were scored from $0-3$ and considered positive when $>1$.

\section{Statistical analysis}

Fisher's exact test was used for association analyses of tumour types or stages with proportion of positive expression. Survival data were analysed with Kaplan-Meier estimator and Cox proportional hazards model. A $z$-test was used to test statistical significance of each coefficient in the model. Deaths due to causes other than endometrial cancer were excluded from analyses of disease specific survival (DSS) or recurrence free survival (RFS). All statistical analyses were carried out using $\mathrm{R}$ (http://www. r-project.org/). Two-sided $P$-values less than 0.05 were considered statistically significant. The 'REMARK' criteria of the National Cancer Institute were used in design, analysis and interpretation (McShane et al, 2005).

\section{RESULTS}

A total of 156 patients that fitted the inclusion criteria were treated in 1997-2002. Clinical and pathological features are summarised in Table 1. Seventy-eight patients died during the observation period, 60 related to endometrial cancer and 18 related to other causes. A total of 64 adverse events were recorded, which included recurrent disease as well as deaths related to endometrial cancer. Three histological groups were formed for analysis: G3 $\mathrm{EEC}=$ group $1 ; \quad \mathrm{USPC}+\mathrm{CC}=$ group 2 and sarcoma + MMMT + mixed tumours = group 3. Of 156 patients included in this study, 131 patients $(83.97 \%)$ had archived paraffin embedded tissue and complete follow-up data available for analysis.

Mean follow-up time was 4.01 years (range, $0.01-11.79$ years). Mean all-stage-, all-histology- overall survival (OS) was 4.01 years (range $0.01-11.79$ years), DSS (114 of 131) was 4.267 years (range $0.01-11.79$ ) and RFS (114 of 131) was 4.108 years (range $0.01-11.79$ ). Patients with low stage (I-II) had a DSS of 5.318 years whereas patients with advanced stage (III-IV) lived significantly shorter with a DSS of 2.24 years (hazard ratio (HR) 4.373, CI 2.55-7.49, $P<0.001$ ) (Table 3).

Figure 1 shows immunohistochemistry with antibodies to CD151, HER-2, E-cadherin, and $\alpha 3 \beta 1, \alpha 6 \beta 1$ integrin subunits. CD151 scored positive in $98.5 \%$ of USPC + CC cases, but less than $50 \%$ of G3 EEC or sarcoma + MMMT + mixed group. CD151 expression was significantly raised in USPC + CC tumour types compared with G3 EEC $(P<0.001)$ and sarcoma+MMMT + mixed $(P<0.001)$. Expression of CD151 was highest in 'triplenegative' tumours as compared with the rest of the cohort $(P<0.001)$. A detailed analysis of CD151, HER-2, ER, PR and p53 expression by stage and histology is presented in Table 2. CD151 showed no specific association with tumour stages. HER-2 positivity $(>1)$ was seen in only eight cases $(6.11 \%)$.

In univariate analyses age, stage, expression of CD151 and histology type, specifically sarcoma/MMMT/mixed group, were significant factors impacting on DSS and RFS (Table 3). Low CD151 expression was associated with significantly worse DSS (HR
Table I Clinicopathological data

\begin{tabular}{|c|c|}
\hline Clinical data & Patients $(n=156)$ \\
\hline Age, mean (s.d., range) & $68.2(11.4,37-89)$ \\
\hline \multicolumn{2}{|l|}{ FIGO stage, $\mathrm{n}(\%)$} \\
\hline I & $87(55.77)$ \\
\hline$\|$ & $14(8.97)$ \\
\hline III & $35(22.4)$ \\
\hline IV & $20(12.8)$ \\
\hline \multicolumn{2}{|l|}{ Histologic type, n (\%) } \\
\hline G3 EEC & $78(50.0)$ \\
\hline UPSC & $33(21.15)$ \\
\hline Clear cell & $9(5.8)$ \\
\hline MMMT & $18(11.5)$ \\
\hline Sarcoma & 14 (8.97) \\
\hline Mixed histology & $4(2.6)$ \\
\hline \multicolumn{2}{|l|}{ Myometrial invasion, n (\%) } \\
\hline$\leqslant 50 \%$ & $58(37.2)$ \\
\hline$>50 \%$ & $94(60.3)$ \\
\hline Missing & 4 \\
\hline \multicolumn{2}{|l|}{ Hysterectomy } \\
\hline Yes & $134(85.9)$ \\
\hline No & $22(14.1)$ \\
\hline \multicolumn{2}{|l|}{ Lymphnodes } \\
\hline Taken & $32(20.5 \mathrm{I})$ \\
\hline Not taken & $124(79.49)$ \\
\hline \multicolumn{2}{|l|}{ Chemotherapy, n (\%) } \\
\hline Yes & $28(17.9)$ \\
\hline No & $128(82.1)$ \\
\hline \multicolumn{2}{|l|}{ Radiotherapy, n (\%) } \\
\hline Yes & $64(41.0)$ \\
\hline No & $92(59.0)$ \\
\hline \multicolumn{2}{|l|}{ Outcome } \\
\hline Alive without disease & $73(46.8)$ \\
\hline Alive with disease & $4(2.6)$ \\
\hline Died of disease & $61(39.1)$ \\
\hline Death of other causes & $18(11.5)$ \\
\hline Observation time mean (range) & I 48 months ( 0.1 - | I. .07 years) \\
\hline Complete data for analysis & $13 \mid$ (83.97\%) \\
\hline Lost for follow-up or missing tissue-samples & $25(16.03 \%)$ \\
\hline
\end{tabular}

Abbreviations: G3 $\mathrm{EEC}=$ grade 3 endometrioid endometrial carcinoma; FIGO = International Federation of Gynaecology and Obstetrics; MMMT = malignant mixed mullerian tumour; UPSC = uterine papillary serous cancer.

$1.816, P=0.02)$ and RFS (HR 1.773, $P=0.02$ ) when compared with strong expression, this is represented in Figure 2. HER-2, ER, PR and 53 expression were not significantly associated with survival. The association of the diminished expression of CD151 with reduced DSS (HR 2.94, $P<0.001$ ) and RFS (HR 2.54, $P<0.001$ ) was even stronger in the triple negative (ER, PR and HER-2-negative) subgroup $(n=88)$. In multivariate analyses age, stage and tumour type maintained significance. CD151 maintained prognostic significance in multivariate analysis for the triple negative subgroup (DSS, $P=0.033$, RFS, $P=0.036$ ) but not for the entire cohort (Table 4). Oestrogen receptor, PR, p53 and HER-2 were not significant factors influencing survival.

The $\alpha 3 \beta 1, \alpha 6 \beta 1$ and E-cadherin were also investigated in one tissue microarray and compared with CD151 expression. Strong staining with $\alpha 6 \beta 1$ integrin was seen in four cores, in 14 cores for $\alpha 3 \beta 1$ strong staining and in 26 cores for E-cadherin staining. There was strong concordance (98\%) of CD151 and E-cadherin staining, 

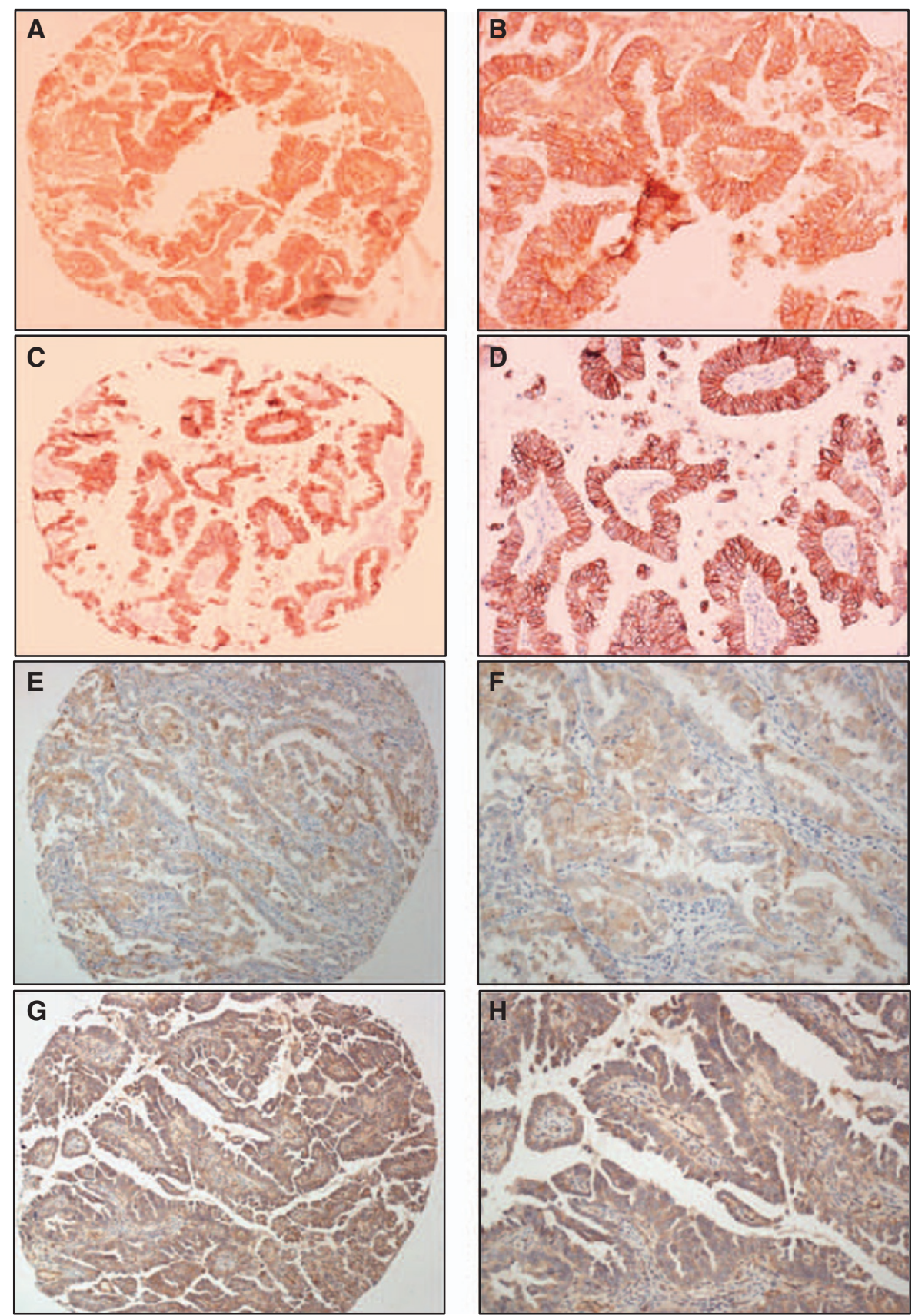

Figure I Immunohistochemistry with antibodies to CDI5I, HER-2, integrins $\alpha 6 \beta|, \alpha 3 \beta|$ and E-cadherin. A and $\mathbf{B}-\mathrm{CDI} 5 \mathrm{I}(\times \mid 00$ and $\times 200$, respectively); $\mathbf{C}$ and $\mathbf{D}$ - E-cadherin ( $\times 100$ and $\times 200$, respectively); $\mathbf{E}$ and $\mathbf{F}$ - integrin $\alpha 3 \beta \mid(\times \mid 00$ and $\times 200$, respectively); $\mathbf{G}$ and $\mathbf{H}-$ integrin $\alpha 6 \beta \mid$ $(\times 100$ and $\times 200$, respectively).

with only 1 of 43 tumours showing discordance in staining (i.e., cores positive for CD151 were positive for E-cadherin staining and cores negative for CD 151 were negative for E-cadherin staining). Only 15 of 43 cores showed concordance with $\alpha 6 \beta 1$ and CD151 staining $(35 \%)$ and 26 of 43 cores $(60 \%)$ showed concordance between $\alpha 3 \beta 1$ and CD151 staining (Figure 1).

\section{DISCUSSION}

This is the first study to evaluate the staining and prognostic significance of tetraspanin CD151 in endometrial carcinoma. We selected tetraspanin CD151 as a marker based on studies in breast cancer, which demonstrated its prognostic utility in a subgroup of invasive ductal carcinomas (Sadej et al, 2009; Novitskaya et al, 2010). Our results show that CD151 is an independent marker for DSS and RFS in poor outcome endometrial carcinoma by univariate analysis and for a triple negative subgroup of patients by multivariate analysis. CD151 is also differentially expressed, with highest expression in the UPSC and CC histology types. Contrary to our expectation, we found that high CD151 expression is positively correlated with improved survival. Thus, this is the first report, which suggests that expression of this tetraspanin protein in tumours may prevent transition to a more malignant phenotype. 
Tetraspanin CDI5I in endometrial cancer

MA Voss et al

Table 2 Clinicopathological features of CDI5I, ER PR, p53 and HER-2 expression by immunohistochemistry

\begin{tabular}{|c|c|c|c|c|c|c|}
\hline & Patients $n$ & $\begin{array}{c}\text { CDI5 I positive } \\
\text { n (\%) }\end{array}$ & $\begin{array}{c}\text { ER positive } \\
n(\%)\end{array}$ & $\begin{array}{c}\text { PR positive } \\
n(\%)\end{array}$ & $\begin{array}{c}\text { P53 positive } \\
n(\%)\end{array}$ & $\begin{array}{c}\text { HER-2 positive } \\
n(\%)\end{array}$ \\
\hline \multicolumn{7}{|l|}{ Stage } \\
\hline III & 28 & $12(42.8)$ & $3(10.7)$ & $2(7.1)$ & $9(32.1)$ & I (3.6) \\
\hline IV & 18 & $10(55.5)$ & $4(22.2)$ & $2(11.1)$ & $4(22.2)$ & $2(11.1)$ \\
\hline$(I-\|)$ & 85 & $50(58.8)$ & $14(16.5)$ & $6(7.1)$ & $18(21.2)$ & $5(5.9)$ \\
\hline \multicolumn{7}{|l|}{ Histology } \\
\hline Group I & 68 & $25(36.76)$ & $15(22.06)$ & $3(4.4)$ & $13(19.1)$ & $3(4.4)$ \\
\hline USPC & 31 & $30(96.7)$ & $6(19.4)$ & $4(12.9)$ & II (35.4) & $4(12.9)$ \\
\hline CC & 7 & $7(100)$ & 0 & I (I4.3) & I (14.3) & I (I4.3) \\
\hline Sarcoma & 13 & $4(30.8)$ & 0 & 0 & $5(38.5)$ & 0 \\
\hline MMMT & 9 & $1(11.1)$ & 0 & $2(22.2)$ & 0 & 0 \\
\hline Tumours mixed histo & 3 & 0 & 0 & 0 & I (33.3) & 0 \\
\hline
\end{tabular}

Abbreviations: $C C=$ clear cell carcinoma; $E R=$ oestrogen receptor; $M M M T=$ malignant mixed mullerian tumour; $P R=$ progesterone receptor; $U P S C=$ uterine papillary serous sarcinoma. ER, PR, p53 and CDI5I are regarded as positive when H-score ₹150. The HER-2 is regarded positive when score > I. Group I comprised of G3 EEC, group II comprised of UPSC and CC, group III comprised of MMMT, sarcoma and mixed mesodermal tumours.

Table 3 Univariate analysis of DSS and RFS

\begin{tabular}{|c|c|c|c|c|c|c|}
\hline & \multicolumn{3}{|c|}{ DSS } & \multicolumn{3}{|c|}{ RFS } \\
\hline & HR & $95 \% \mathrm{Cl}$ & $\mathbf{P}$ & HR & $95 \% \mathrm{Cl}$ & $\mathbf{P}$ \\
\hline Stage (I, II vs III, IV) & 4.373 & $2.55-7.49$ & $<0.001$ & 3.965 & $2.37-6.62$ & $<0.001$ \\
\hline \multicolumn{7}{|l|}{ Histology ${ }^{a}$} \\
\hline Group II vs group I & 1.069 & $0.55-2.067$ & 0.84 & 1.056 & $0.56-1.96$ & 0.86 \\
\hline CDI5I (in ER, PR and HER-2 negative tumours) & 2.94 & $1.50-5.74$ & $<\mathbf{0 . 0 0 1}$ & 2.541 & $1.37-4.7 \mid$ & 0.008 \\
\hline HER-2 & 1.541 & $0.55-4.26$ & 0.402 & 1.408 & $0.51-3.88$ & 0.506 \\
\hline P53 & 1.283 & $0.71-2.32$ & 0.409 & 1.112 & $0.62-1.99$ & 0.72 \\
\hline ER & 0.815 & $0.38-1.72$ & 0.591 & 0.851 & $0.419-1.72$ & 0.655 \\
\hline PR & 0.962 & $0.34-2.66$ & 0.94 & 0.864 & $0.31-2.38$ & 0.77 \\
\hline
\end{tabular}

Abbreviations: $\mathrm{Cl}=$ confidence interval; $\mathrm{DSS}=$ disease specific survival; $\mathrm{ER}=$ oestrogen receptor; $\mathrm{HR}=$ hazard ratio; $\mathrm{PR}=$ progesterone receptor; $\mathrm{RFS}=$ recurrence free survival. Univariate analysis of age was performed in a linear manner, therefore, there is no referent variable. ${ }^{a}$ Univariate analysis of histology carried out with endometrioid histology as reference. Significant $P$-values for CDI5I are in bold.
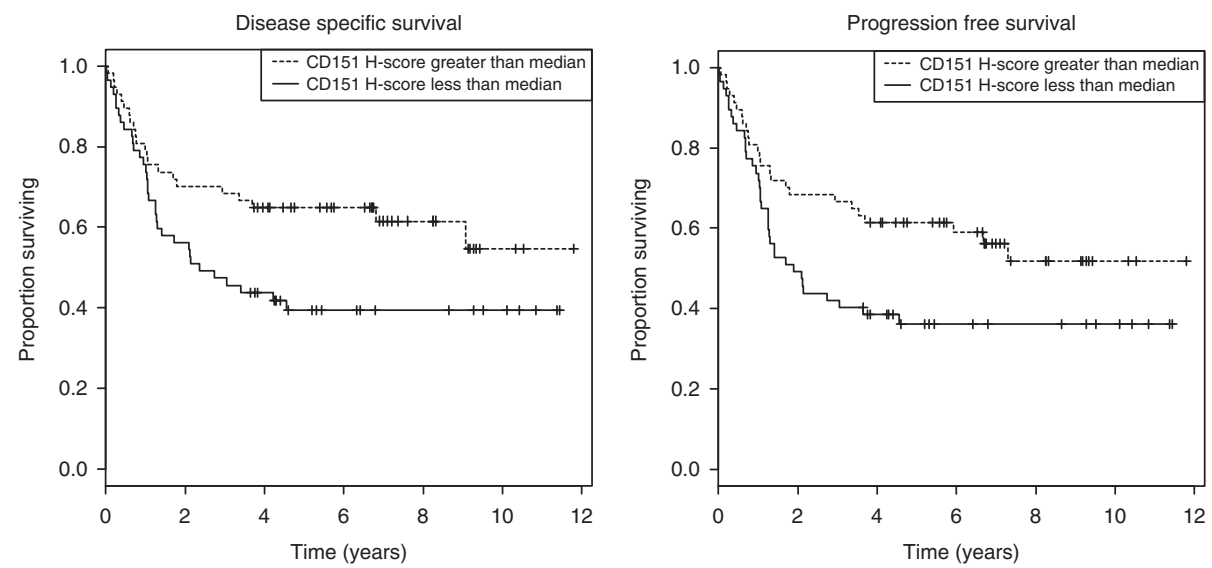

Figure 2 Kaplan-Meier survival curves demonstrating effect of CDI5I expression on DSS and RFS in the entire cohort. For DSS, the hazard ratios of CDI5I greater than median is $1.816(95 \%$ confidence interval $1.060-3.109, P=0.02746)$ and for RFS is 1.773 (95\% confidence interval I.062-2.96I, $P=0.02647$ ) indicating that there is a significant survival benefit in the group overexpressing CDI5I. 
Table 4 Multivariate analysis of DSS and RFS

\begin{tabular}{|c|c|c|c|c|c|c|}
\hline & \multicolumn{3}{|c|}{ DSS } & \multicolumn{3}{|c|}{ RFS } \\
\hline & HR & OR - 95\%Cl & $P$-value & HR & OR $-95 \% \mathrm{Cl}$ & $P$-value \\
\hline Stage & 5.0119 & $2.8090-8.942$ & $<0.001$ & 4.5366 & $2.6132-7.876$ & $<0.001$ \\
\hline \multicolumn{7}{|l|}{ Histology } \\
\hline Group II & 1.0603 & $0.4215-2.667$ & n.s. & 1.0757 & $0.4534-2.552$ & n.s. \\
\hline CDI5I (in ER, PR, HER-2 negative tumours) & 3.168 & $1.1005-9.123$ & 0.033 & 2.792 & $1.0682-7.299$ & 0.036 \\
\hline
\end{tabular}

Abbreviations: $\mathrm{Cl}=$ confidence interval; $\mathrm{DSS}=$ disease specific survival; $\mathrm{ER}=$ oestrogen receptor; $\mathrm{HR}=$ hazard ratio; $\mathrm{n} . \mathrm{s}$. = non-significant; $\mathrm{OR}=$ odds ratio; $\mathrm{PR}=$ progesterone receptor; RFS = recurrence free survival. A multivariate regression model was designed utilizing a backwards elimination. Significant $P$-values for CDI5I are in bold.

The strengths of this study are the long duration of follow-up and high numbers of poor prognostic types of tumours. Our cohort includes G3 endometrioid endometrial cancers, which are usually not included into type II endometrial cancers. However, they fit the criteria in so far as they demonstrate more aggressive behaviour and are of significantly poorer prognosis ( $58 \% 5$ year survival) than low-grade endometrioid cancers (Bokhman, 1983). In addition, analyses of survival outcome between histological groups I and II show no difference in RFS or DSS (data not shown). Additionally we included sarcomas, carcinosarcomas and uterine tumours of mixed histology for the same reason - they are also poor prognosis tumours with currently no adjuvant treatment that has shown to clearly improve survival (Sutton et al, 2000; DeniaudAlexandre et al, 2001; Weitmann et al, 2002; Giuntoli et al, 2003; Livi et al, 2003; Toyoshima et al, 2004). Although the tissue set contains divergent histology types, clinically these tumours result in poor outcome and justify being investigated together.

Increased expression of CD151 also correlates with advanced tumour grades and poor prognosis in other tumours. Ang et al, (2004) showed that overall survival was reduced in prostate cancer tumours where CD151 was overexpressed. This was consistent with findings in lung cancer (Tokuhara et al, 2001). In colon cancer, changes in expression of CD151 appear to be more complex. An early report has described that increased expression levels of this tetraspanin correlated with a more advanced stage of the disease (Zijlstra et al, 2008). However, a more recent study has found that expression of CD151 protein was reduced in human colon cancers compared with surrounding normal tissue, in which it is strongly expressed on the basal and lateral surfaces of epithelial cells (Chien et al, 2008). The authors hypothesised that intra-tumoural activation of hypoxia-inducible factor 1 led to inhibition of CD151 expression and this repressed the function of E-cadherin (Chien et al, 2008), thereby dramatically reducing cell-to-cell adhesion and thus increasing invasion and metastasis. Interestingly, it was also found that the expression level of CD151 in the metastatic lesions was increased when compared with primary colon cancer tissues.

Although the exact biochemical function of CD151 is still unknown, evidence shows that it is involved in signal transduction (Yauch et al, 1998; Zhang et al, 2001), cell adhesion (Hasegawa et al, 1998), and motility (Testa et al, 1999). In relation to tumour metastasis, experiments using anti-CD151 mAb have established that this tetraspanin may contribute to an early step in the formation of secondary metastatic lesions by mediating invasiveness of primary tumour cells into surrounding stromal tissues and vascular intravasation (Testa et al, 1999). More recently, we have

\section{REFERENCES}

Ang J, Lijovic M, Ashman LK, Kan K, Frauman AG (2004) CD151 protein expression predicts the clinical outcome of low-grade primary prostate shown that CD151 can also regulate recruitment of breast cancer cells to the lungs and growth of the metastatic lesion (Sadej et al, 2010). Thus, tetraspanin CD151 may be involved in various aspects of the metastatic cascade.

Although our results strongly suggest that CD151 may have an important role in tumourigenesis in some histology types of endometrial cancer, the mode of its action remains unknown. Holcomb et al, (2002) examined E-cadherin in endometrial carcinoma and found that papillary serous and clear cell carcinomas show significantly reduced E-cadherin expression in comparison with endometrioid tumours $(P=0.01)$. Thus, one possibility might be that $\mathrm{CD} 151$ counteracts the metastatic progression of endometrial cancer by stabilizing E-cadherin based cell-cell interactions. In this regard, it is noteworthy that we found a strong correlation in the expression levels of E-cadherin and CD151 in cancer samples. Alternatively, CD151 may act through laminin-binding integrins, its main molecular partners in tetraspanin microdomains, by strengthening interactions of endometrial cells with laminin components of the basement membrane. Detailed immunohistochemical analyses of endometrial cancer tissues will be necessary to address this issue in the future.

So far, treatment options in type II cancers are largely limited to surgical- and/or chemotherapy regimen, which have not altered the poor prognosis of these tumours.

There is an unmet clinical need for robust prognostic markers that can help in guiding therapeutic decisions in these tumour types, particularly at recurrence and at advanced stage. This study suggests that, in patients with CD151 positive tumours, survival is significantly better than those with CD151 negative tumours. This could be highly clinically relevant as even in a triple negative marker group, CD151 is highly prognostic of both DSS and RFS. A larger prospective study of CD151 in this group of cancers is now being established to confirm these findings. An enhanced understanding of the molecular basis of these tumours will also aid in the development of novel, targeted therapies.

\section{ACKNOWLEDGEMENTS}

We gratefully acknowledge the Cobalt appeal fund, Cheltenham for their funding support of this study, Dr D Brennan, UCL, Dublin, for help with construction of tissue microarrays, Dr Zuzana Kyrcowa for support with pathology and the South West Public Health Observatory. 
Bansal N, Yendluri V, Wenham RM (2009) The molecular biology of endometrial cancers and the implications for pathogenesis, classification, and targeted therapies. Cancer Control 16: 8-13

Berditchevski F, Chang S, Bodorova J, Hemler ME (1997) Generation of monoclonal antibodies to integrin-associated proteins. Evidence that alpha3beta1 complexes with EMMPRIN/basigin/OX47/M6. J Biol Chem 272: $29174-29180$

Bokhman JV (1983) Two pathogenetic types of endometrial carcinoma. Gynecol Oncol 15: 10-17

Bray F, Dos Santos Silva I, Moller H, Weiderpass E (2005) Endometrial cancer incidence trends in Europe: underlying determinants and prospects for prevention. Cancer Epidemiol Biomarkers Prev 14: 1132 - 1142

Budwit-Novotny DA, McCarty KS, Cox EB, Soper JT, Mutch DG, Creasman WT, Flowers JL, McCarty Jr KS (1986) Immunohistochemical analyses of estrogen receptor in endometrial adenocarcinoma using a monoclonal antibody. Cancer Res 46: 5419-5425

Cancer Research UK (2010) Vol. 2010. http://info.cancerresearchuk.org/ cancerstats/types/uterus/

Carcangiu ML, Chambers JT (1992) Uterine papillary serous carcinoma: a study on 108 cases with emphasis on the prognostic significance of associated endometrioid carcinoma, absence of invasion, and concomitant ovarian carcinoma. Gynecol Oncol 47: 298-305

Carcangiu ML, Chambers JT (1995) Early pathologic stage clear cell carcinoma and uterine papillary serous carcinoma of the endometrium: comparison of clinicopathologic features and survival. Int $J$ Gynecol Pathol 14: $30-38$

Chien CW, Lin SC, Lai YY, Lin BW, Lee JC, Tsai SJ (2008) Regulation of CD151 by hypoxia controls cell adhesion and metastasis in colorectal cancer. Clin Cancer Res 14: 8043-8051

Deniaud-Alexandre E, Chauveinc L, de la Rochefordiere A, Sastre X, Clough KB (2001) [Role of adjuvant therapy in uterine sarcoma: experience of the Curie Institute]. Cancer Radiother 5: 743-749

Ferlay J, Shin HR, Bray F, Forman D, Mathers C, Parkin DM (2010) Estimates of worldwide burden of cancer in 2008: GLOBOCAN 2008. Int $J$ Cancer 127: 2893-2917

Giuntoli II RL, Metzinger DS, DiMarco CS, Cha SS, Sloan JA, Keeney GL, Gostout BS (2003) Retrospective review of 208 patients with leiomyosarcoma of the uterus: prognostic indicators, surgical management, and adjuvant therapy. Gynecol Oncol 89: 460-469

Hasegawa H, Nomura T, Kishimoto K, Yanagisawa K, Fujita S (1998) SFA1/PETA-3 (CD151), a member of the transmembrane 4 superfamily, associates preferentially with alpha 5 beta 1 integrin and regulates adhesion of human $\mathrm{T}$ cell leukemia virus type 1 -infected $\mathrm{T}$ cells to fibronectin. J Immunol 161: 3087-3095

Hemler ME (2008) Targeting of tetraspanin proteins-potential benefits and strategies. Nat Rev Drug Discov 7: 747-758

Holcomb K, Delatorre R, Pedemonte B, McLeod C, Anderson L, Chambers J (2002) E-cadherin expression in endometrioid, papillary serous, and clear cell carcinoma of the endometrium. Obstet Gynecol 100: 1290-1295

Humber C, Tierney J, Symonds P, Collingwood M, Kirwan J, Williams C, Green J (2005) Chemotherapy for advanced, recurrent or metastatic endometrial carcinoma. Cochrane Database Syst Rev. Art. No. CD003915

Katz RL, Patel S, Sneige N, Fritsche Jr HA, Hortobagyi GN, Ames FC, Brooks T, Ordonez NG (1990) Comparison of immunocytochemical and biochemical assays for estrogen receptor in fine needle aspirates and histologic sections from breast carcinomas. Breast Cancer Res Treat 15: $191-203$

Kitchener H, Swart AM, Qian Q, Amos C, Parmar MK (2009) Efficacy of systematic pelvic lymphadenectomy in endometrial cancer (MRC ASTEC trial): a randomised study. Lancet 373: $125-136$

Kohler MF, Carney P, Dodge R, Soper JT, Clarke-Pearson DL, Marks JR, Berchuck A (1996) p53 overexpression in advanced-stage endometrial adenocarcinoma. Am J Obstet Gynecol 175: $1246-1252$

Lammerding J, Kazarov AR, Huang H, Lee RT, Hemler ME (2003) Tetraspanin CD151 regulates alpha6betal integrin adhesion strengthening. Proc Natl Acad Sci USA 100: 7616-7621

Lax SF, Kurman RJ (1997) A dualistic model for endometrial carcinogenesis based on immunohistochemical and molecular genetic analyses. Verh Dtsch Ges Pathol 81: 228-232

Levenback C, Burke TW, Silva E, Morris M, Gershenson DM, Kavanagh JJ, Wharton JT (1992) Uterine papillary serous carcinoma (UPSC) treated with cisplatin, doxorubicin, and cyclophosphamide (PAC). Gynecol Oncol 46: $317-321$

Livi L, Paiar F, Shah N, Blake P, Villanucci A, Amunni G, Barca R, Judson I, Lodge N, Meldolesi E, Simontacchi G, Piperno G, Galardi A, Scoccianti S,
Biti GP, Harmer C (2003) Uterine sarcoma: twenty-seven years of experience. Int J Radiat Oncol Biol Phys 57: 1366-1373

Maxwell GL, Risinger JI, Alvarez AA, Barrett JC, Berchuck A (2001) Favorable survival associated with microsatellite instability in endometrioid endometrial cancers. Obstet Gynecol 97: 417-422

McShane LM, Altman DG, Sauerbrei W, Taube SE, Gion M, Clark GM (2005) REporting recommendations for tumour MARKer prognostic studies (REMARK). Br J Cancer 93: 387-391

Morrison C, Zanagnolo V, Ramirez N, Cohn DE, Kelbick N, Copeland L, Maxwell GL, Fowler JM (2006) HER-2 is an independent prognostic factor in endometrial cancer: association with outcome in a large cohort of surgically staged patients. J Clin Oncol 24: 2376-2385

Novitskaya V, Romanska H, Dawoud M, Jones JL, Berditchevski F (2010) Tetraspanin CD151 regulates growth of mammary epithelial cells in three-dimensional extracellular matrix: implication for mammary ductal carcinoma in situ. Cancer Res 70: 4698-4708

Risinger JI, Hayes K, Maxwell GL, Carney ME, Dodge RK, Barrett JC, Berchuck A (1998) PTEN mutation in endometrial cancers is associated with favorable clinical and pathologic characteristics. Clin Cancer Res 4: $3005-3010$

Rose PG (1996) Endometrial carcinoma. N Engl J Med 335: 640-649

Sadej R, Romanska H, Baldwin G, Gkirtzimanaki K, Novitskaya V, Filer AD, Krcova Z, Kusinska R, Ehrmann J, Buckley CD, Kordek R, Potemski P, Eliopoulos AG, Lalani el N, Berditchevski F (2009) CD151 regulates tumorigenesis by modulating the communication between tumor cells and endothelium. Mol Cancer Res 7: 787-798

Sadej R, Romanska H, Kavanagh D, Baldwin G, Takahashi T, Kalia N, Berditchevski F (2010) Tetraspanin CD151 regulates transforming growth factor beta signaling: implication in tumor metastasis. Cancer Res 70: 6059-6070

Sincock PM, Fitter S, Parton RG, Berndt MC, Gamble JR, Ashman LK (1999) PETA-3/CD151, a member of the transmembrane 4 superfamily, is localised to the plasma membrane and endocytic system of endothelial cells, associates with multiple integrins and modulates cell function. J Cell Sci 112(Pt 6): $833-844$

Singh P, Smith CL, Cheetham G, Dodd TJ, Davy ML (2008) Serous carcinoma of the uterus-determination of HER-2/neu status using immunohistochemistry, chromogenic in situ hybridization, and quantitative polymerase chain reaction techniques: its significance and clinical correlation. Int J Gynecol Cancer 18: 1344-1351

Stipp CS (2010) Laminin-binding integrins and their tetraspanin partners as potential antimetastatic targets. Expert Rev Mol Med 12: e3

Sutton G, Brunetto VL, Kilgore L, Soper JT, McGehee R, Olt G, Lentz SS, Sorosky J, Hsiu JG (2000) A phase III trial of ifosfamide with or without cisplatin in carcinosarcoma of the uterus: A Gynecologic Oncology Group Study. Gynecol Oncol 79: $147-153$

Testa JE, Brooks PC, Lin JM, Quigley JP (1999) Eukaryotic expression cloning with an antimetastatic monoclonal antibody identifies a tetraspanin (PETA-3/CD151) as an effector of human tumor cell migration and metastasis. Cancer Res 59: $3812-3820$

Tokuhara T, Hasegawa H, Hattori N, Ishida H, Taki T, Tachibana S, Sasaki S, Miyake M (2001) Clinical significance of CD151 gene expression in non-small cell lung cancer. Clin Cancer Res 7: 4109-4114

Toyoshima M, Akahira J, Matsunaga G, Niikura H, Ito K, Yaegashi N, Tase T (2004) Clinical experience with combination paclitaxel and carboplatin therapy for advanced or recurrent carcinosarcoma of the uterus. Gynecol Oncol 94: 774-778

Weitmann HD, Kucera H, Knocke TH, Potter R (2002) Surgery and adjuvant radiation therapy of endometrial stromal sarcoma. Wien Klin Wochenschr 114: 44-49

Wilder JL, Shajahan S, Khattar NH, Wilder DM, Yin J, Rushing RS, Beaven R, Kaetzel C, Ueland FR, van Nagell JR, Kryscio RJ, Lele SM (2004) Tamoxifen-associated malignant endometrial tumors: pathologic features and expression of hormone receptors estrogen-alpha, estrogen-beta and progesterone; a case controlled study. Gynecol Oncol 92: 553-558

Wolff AC, Hammond ME, Schwartz JN, Hagerty KL, Allred DC, Cote RJ, Dowsett M, Fitzgibbons PL, Hanna WM, Langer A, McShane LM, Paik S, Pegram MD, Perez EA, Press MF, Rhodes A, Sturgeon C, Taube SE, Tubbs R, Vance GH, van de Vijver M, Wheeler TM, Hayes DF (2007) American Society of Clinical Oncology/College of American Pathologists guideline recommendations for human epidermal growth factor receptor 2 testing in breast cancer. J Clin Oncol 25: 118-145

Yanez-Mo M, Alfranca A, Cabanas C, Marazuela M, Tejedor R, Ursa MA, Ashman LK, de Landazuri MO, Sanchez-Madrid F (1998) Regulation of endothelial cell motility by complexes of tetraspan molecules 
CD81/TAPA-1 and CD151/PETA-3 with alpha3 beta1 integrin localized at endothelial lateral junctions. J Cell Biol 141: $791-804$

Yauch RL, Berditchevski F, Harler MB, Reichner J, Hemler ME (1998) Highly stoichiometric, stable, and specific association of integrin alpha3beta1 with $\mathrm{CD} 151$ provides a major link to phosphatidylinositol 4-kinase, and may regulate cell migration. Mol Biol Cell 9: $2751-2765$
Zhang XA, Bontrager AL, Hemler ME (2001) Transmembrane-4 superfamily proteins associate with activated protein kinase C (PKC) and link PKC to specific beta(1) integrins. J Biol Chem 276: 25005-25013

Zijlstra A, Lewis J, Degryse B, Stuhlmann H, Quigley JP (2008) The inhibition of tumor cell intravasation and subsequent metastasis via regulation of in vivo tumor cell motility by the tetraspanin CD151. Cancer Cell 13: 221-234 